\title{
EDUCAÇÃO AMBIENTAL: REFLEXÕES SOBRE A PRÁTICA DE UM GRUPO DE PROFESSORES DE QUÍMICA
}

\section{Environmental education: considerations about the practice of a Chemistry teachers group}

\author{
Rosana Franzen Leite ${ }^{1}$ \\ Maria Aparecida Rodrigues ${ }^{2}$
}

\begin{abstract}
Resumo: Neste artigo, discutimos alguns aspectos da prática pedagógica de professores de química, com relação à Educação Ambiental no Ensino Médio. Participaram da pesquisa 13 professores de química do Ensino Médio de um município do estado do Paraná (Brasil), que responderam a uma entrevista semiestruturada. Dos discursos analisados, emergiram: as características da Educação Ambiental que esses professores procuram desenvolver em suas aulas; os objetivos de se abordarem as questões ambientais; experiências vivenciadas com a temática ambiental, e conteúdos que, na visão dos entrevistados, possibilitam relacionar conceitos químicos ao meio ambiente. Em boa parte das respostas, identifica-se uma concepção conservadora de Educação Ambiental, refletindo a maneira ainda tímida por meio da qual o professor trabalha essa temática.
\end{abstract}

Palavras-chave: Ensino Médio. Educação Ambiental. Prática pedagógica.

\begin{abstract}
This paper discusses some aspects of the pedagogical practice of Chemistry teachers, regarding the environment education theme in High School. Thirteen High School Chemistry teachers from a Paraná state's city in Brazil took part in this study, by answering to a semi structured interview. From the analyzed discourses, the aspects of Environmental Education that these teachers try to develop in their classes, the goals for approaching environmental issues, the experiences with the environmental theme, and the contents which make possible to establish relations between Chemistry concepts and environment for those interviewees came to light. In many answers, a conservative conception of Environmental Education is identified that reflects the way by which the teacher deals with this issue, even if in an incipient way.
\end{abstract}

Keywords: High School. Environmental Education. Pedagogical practice.

\footnotetext{
${ }^{1}$ Licenciatura em Química. Mestranda em Educação para a Ciência e a Matemática, Centro de Ciências Exatas, Universidade Estadual de Maringá (UEM). Maringá, PR, Brasil. <rosanafleite@yahoo.com.br>

${ }^{2}$ Licenciatura em Química, doutora em Ciências. Docente, Departamento de Química, UEM. Maringá, PR, Brasil. <aparecidar@gmail.com>

${ }^{1}$ Rua Nilo Cairo, 413

Jardim Maracanã - Toledo, PR

85.910-140 
Leite, R. F.; Rodrigues, M. A.

\section{Introdução}

Neste estudo, investigamos como um grupo de professores de Química do Ensino Médio aborda as questões ambientais nas aulas de Química, partindo do pressuposto de que o desenvolvimento da Educação Ambiental, no contexto da escola, pode ser uma das possibilidades de provocar mudanças consideradas tão necessárias no pensar e agir dos sujeitos com relação ao ambiente. Nesse contexto, Penteado (2001) afirma que, diante da situação de degradação e de conflito de interesses que envolvem o meio ambiente, é na escola que tais aspectos podem ser conjugados. Sabemos que a inserção da Educação Ambiental (EA) nos diferentes níveis de ensino, de forma que permeie todas as disciplinas do currículo, é uma recomendação da Lei Federal 9.795/99 (BRASIL, 2009), e que o tema Meio Ambiente é um dos temas transversais sugeridos pelos PCNs (BRASIL, 1997). No entanto, entendemos que, mais do que buscar atender às questões legais, é importante a problematização de aspectos ambientais no ensino de Química, pois, além de propiciar a contextualização dos conceitos químicos, diferencia o olhar de professores e alunos em relação ao meio ambiente.

Em consonância com esse pensamento, Santos e Mortimer (2000) indicam, dentre os temas possíveis de serem trabalhados em uma abordagem CTSA, alguns que merecem destaque: a exploração mineral e suas consequências; os desenvolvimentos científico, social e tecnológico; a ocupação e a poluição ambiental; a produção e o tratamento do lixo, assim como seu impacto no meio ambiente; o desenvolvimento da agricultura e os riscos ambientais das monoculturas dos latifúndios; as fontes energéticas e os efeitos ambientais e políticos; a preservação ambiental, as políticas de meio ambiente e o desmatamento.

Corroborando essas relações, Santos e Schnetzler (2003) destacam o tema Meio Ambiente como um dos temas sociais que permitem desenvolver os conceitos químicos e, ainda, evidenciar as relações entre ciência, tecnologia e sociedade.

Nesse contexto, concordamos com Loureiro (2004), quando este afirma que uma Educação Ambiental Crítica - de caráter transformador e emancipatório - se torna imprescindível como possibilidade de abordagem das questões ambientais, levando em consideração todos os fatores envolvidos e, consequentemente, possibilitando um ensino contextualizado e o desenvolvimento, nos alunos, de atitudes responsáveis relacionadas ao meio ambiente.

$\mathrm{Na}$ sequência, apresentamos características de algumas tendências de EA, dando ênfase à EA crítica, transformadora e emancipatória, a qual questiona abordagens comportamentalistas e reducionistas, bem como a dissociação entre natureza e cultura, sociedade e ambiente.

\section{Educação Ambiental crítica, transformadora e emancipatória}

Crítica, transformadora e emancipatória são adjetivos que surgem como crítica a uma determinada EA, praticada sem objetivo de mudança, sem relevância no aspecto social, ou seja, é "aquela cujos ensinamentos conduzem ao uso racional dos recursos naturais e à manutenção de um nível ótimo de produtividade dos ecossistemas naturais ou gerenciados pelos seres humanos" (BRÜGGER, 2004, p. 35), sendo conhecida como EA convencional (LOUREIRO, 2004; LIMA, 2004), conservadora (GUIMARÃES, 2004) ou conservacionista 
(BRÜGGER, 2004). Dessa forma, termos como crítica, transformadora e emancipatória, entre outros, assim como libertadora, popular etc., são adjetivos que se aproximam do modo de compreender a educação e a inserção de nossa espécie na sociedade (LOUREIRO, 2004). Assim, a pedagogia freireana contribui, de maneira significativa, para a proposição teórica e metodológica dessa EA (LIMA, 2004).

Cabe esclarecer aqui que tais adjetivos não são considerados sinônimos, e sim, aspectos que se unem para descrever as perspectivas de uma Educação Ambiental que não seja reducionista nem associal; pelo contrário, opõe-se a esse pensamento, questionando-o e propondo uma integração entre sociedade e ambiente.

Todos esses adjetivos possuem, sobretudo, o mérito de questionarem abordagens comportamentalistas, reducionistas ou, mesmo, dualistas da relação cultura-natureza, estimulando o diálogo democrático entre os educadores ambientais (LOUREIRO, 2004). O mesmo autor ainda complementa:

A educação ambiental não se refere exclusivamente às relações vistas como naturais ou ecológicas como se as sociais fossem a negação direta destas, recaindo no dualismo, mas sim a todas as relações que nos situam no planeta e que se dão em sociedade - dimensão inerente à nossa condição como espécie. Assim, o educar "ambientalmente" se define pela unicidade dos processos que problematizam os atributos dos grupos sociais, com os que agem nas esferas política e econômica - quanto propicia caminhos sustentáveis e sinaliza para novos padrões societários. (LOUREIRO, 2004, p. 79)

Dessa forma, essas tendências se opõem à EA dita Convencional, Conservadora ou Conservacionista (LOUREIRO, 2004; LIMA, 2004; GUIMARÃES, 2004; BRÜGGER, 2004), que pode ser caracterizada como aquela que apresenta os seguintes aspectos:

. dá ênfase à dimensão individual, deixando em segundo plano a compreensão de que a relação do sujeito com o mundo ocorre por várias mediações sociais;

. é entendida como ato individual, despolitizado e pouco articulado às ações coletivas, à problematização e à transformação da realidade. Idealiza ingenuamente que um somatório de ações individuais provocará as mudanças necessárias, faltando a complexidade no entendimento das relações que constituem o ser;

. "biologiza" o que possui caráter social, ignorando que as relações atualmente se dão com predomínio do capitalismo - o sistema econômico vigente - que não é apenas poluidor, mas também explorador de muitas espécies. Dessa forma, o homem é reduzido a um organismo biológico, associal e a-histórico, que acaba sendo responsabilizado por toda a degradação existente; além disso, esse tipo de EA é, também, apresentada de forma descontextualizada (LOUREIRO, 2004).

Há, ainda, a definição que Guimarães (2004, p. 26) fornece, destacando que se trata de uma EA que "se alicerça nessa visão de mundo que fragmenta a realidade, simplificando e reduzindo-a, perdendo a riqueza e a diversidade da relação". Nesse sentido, o autor ressalta: 
Essa concepção de Educação, ao se colocar inapta de transformar uma realidade (a qual ela própria é um dos mecanismos de reprodução), conserva o movimento de constituição da realidade de acordo com os interesses dominantes - a lógica do capital. (GUIMARÃES, 2004, p. 26)

Exemplos típicos desse tipo de EA, presentes nas escolas, são as comemorações, tais como: Dia da Árvore, Dia do Meio Ambiente, Dia da Água, pois, nessas datas, várias manifestações de comportamento ecologicamente correto são apresentadas e, até mesmo, discutidas. Porém, uma vez passadas as comemorações, esquecem-se os temas discutidos e todos voltam à sua rotina normal, ou seja, não há continuidade dos trabalhos e, consequentemente, não há mudança de pensamento nem de atitude.

Contrapondo-se a essa tendência, a EA crítica, transformadora e emancipatória possui os seguintes objetivos:

i. Promover a compreensão dos problemas ambientais em todas as suas dimensões (social, biológica, subjetiva), considerando o ambiente como um conjunto de inter-relações entre o mundo social e o natural, mediadas pelos saberes locais, científicos e tradicionais;

ii. Atuar não apenas na escola, mas também fora dela, questionando e desafiando os sujeitos para a participação na busca das soluções, buscando integração entre a escola e o ambiente, local e regional, no qual está inserida;

iii. Situar o educador como mediador das relações socioeducativas, coordenando ações, pesquisas e reflexões, não apenas escolares, mas também administrativas, que oportunizem novos processos de aprendizagem (CARVALHO, 2004);

iv. Essa educação busca redefinir o modo pelo qual nos relacionamos conosco, com as demais espécies e com o planeta. Trata-se de um processo de politização e "publicização" da problemática ambiental, no qual o indivíduo, agindo coletivamente, transforma a si e à realidade. Nesse processo, não se permitem dissociações, tais como: natureza vs. cultura, ou sociedade $v s$. ambiente;

v. Quanto à metodologia, a EA Transformadora embasa seus procedimentos na participação e no exercício da cidadania, com o intuito de definir, de forma democrática, o que é sustentável para a vida em cada contexto;

vi. Educar no sentido de transformar significa romper com as práticas sociais contrárias à desigualdade social, pautando-se, sobretudo, em mudanças éticas (LOUREIRO, 2004).

Destacamos, ainda, como o principal fundamento da EA Emancipatória, a crítica aos reducionismos, os quais, geralmente, são atribuídos à EA. Assim, por exemplo, analisar apenas os efeitos dos impactos ambientais, em detrimento das causas geradoras dos mesmos, é uma forma de reducionismo, pois fragmenta algo que não pode ser superado apenas pela eliminação dos sintomas aparentes. Isto porque a eliminação dos sintomas, sem reflexão sobre as causas formadoras, traz a ilusão de mudança, mas não transforma a realidade do problema (LIMA, 2004).

Trata-se, então, do que Floriani e Knechtel (2003, p. 55) denominam Educação Socioambiental, uma vez que essa EA valoriza o diálogo dos diversos saberes cujo critério de validade do conhecimento "está na relevância que traz para a transformação na perspectiva crítica, transformadora para a vida". 
Dessa forma, investigar o trabalho dos professores de Química com relação às abordagens enfatizadas faz-se necessário, devido à importância dos aspectos políticos, econômicos e sociais e, também, pela urgência de modificações em um ensino de Química que ainda prioriza a memorização de nomes, fórmulas e a preparação para o vestibular.

\section{Metodologia da investigação}

Este estudo é parte de uma pesquisa maior, desenvolvida em uma dissertação de mestrado, na qual investigamos como um grupo de professores de Química do Ensino Médio aborda questões ambientais em suas aulas, a partir do que se constatou em suas falas. Participaram da pesquisa 13 professores, sendo quatro do sexo masculino e nove do sexo feminino. Destes, 11 são professores da rede estadual e estão vinculados a nove colégios públicos estaduais. Os outros dois são da rede federal e atuam ou atuaram no Ensino Médio regular e Supletivo da rede pública estadual, além da rede particular. Vale ressaltar, ainda, que quatro dos professores selecionados atuam, também, no Ensino Superior.

Para a realização desta pesquisa, utilizamos entrevistas semiestruturadas, nas quais o entrevistador se vale de perguntas guias, que dispensam ordem específica de aplicação; assim, cabe ao entrevistador aprofundar ou não determinada questão, de acordo com o direcionamento da entrevista, proporcionando certa liberdade ao entrevistado (LÜDKE; ANDRÉ, 1986). Elaboramos um questionário com 12 questões que pudessem exprimir como o professor de Química trata dos temas ambientais em suas aulas, bem como o que ele pensa sobre meio ambiente e educação ambiental. Essas questões são aqui apresentadas: Q01) Quando você pensa em meio ambiente, o que lhe vem à mente? Q02) Hoje vivenciamos inúmeros problemas ambientais, como a poluição do ar, da água e do solo, o buraco na camada de ozônio, o aquecimento global, entre outros. A Química teria alguma implicação nessas mudanças? Por quê? Q03) É possível ensinar Química utilizando os temas relacionados ao meio ambiente? Por quê? Q04) Quais são suas intenções ao relacionar o meio ambiente aos conteúdos químicos? Q05) Quais conhecimentos de Química poderiam ser trabalhados, por exemplo, com o tema lixo? Como faria isso? Q06) Além do conhecimento químico, que outros aspectos você trabalha com seus alunos, quando trata esses temas em sala de aula? Q07) Descreva uma ou mais experiências que envolvem a Química e o meio ambiente, que você já tenha trabalhado com seus alunos. Q08) Há limites e dificuldades para se trabalhar com essa temática? Quais são e por quê? Q09) Com relação à articulação com outras disciplinas, em algum momento de sua prática, isso ocorreu ou ocorre? O que é feito para que a articulação apresente resultado positivo? Q10) Além do tema meio ambiente, como você trabalha a relação ciência, tecnologia e sociedade (CTS) em suas aulas? E quanto aos princípios da Química Verde, você os aborda de que maneira? Q11) Fale-me do seu curso de graduação no que se refere à educação ambiental. Q12) Há mais alguma coisa que deseje falar, algo que tenha desenvolvido, ou algo que queira destacar, alguma ressalva que queira fazer?

As entrevistas foram realizadas em local escolhido pelo professor, com duração média de cinquenta minutos. Os depoimentos foram gravados em mp4, transcritos na íntegra (THOMPSON, 2002) e, posteriormente, analisados por meio da Análise de Conteúdo (BARDIN, 1977). 
Leite, R. F.; Rodrigues, M. A.

\section{Discussão dos resultados}

As reflexões sobre os dados obtidos com as entrevistas, bem como a discussão que segue cada dado emergiram do confronto de tais dados com o referencial teórico apresentado. A análise de conteúdo permitiu-nos estabelecer seis categorias: representações de meio ambiente; a EA na formação dos professores; a prática pedagógica do professor; características da prática pedagógica em relação à EA; obstáculos para abordagens de temas sociais e abordagem das relações CTS. Entretanto, neste trabalho, optamos por discutir apenas a categoria referente às características da prática pedagógica relativa à Educação Ambiental, pela sua relevância para o debate acerca da inserção da EA na escola.

\section{Categoria 1: características da prática pedagógica em relação à Educação Ambiental}

Nesta categoria, que é composta por 8 (oito) subcategorias, evidenciamos as características da prática do professor em relação à $\mathrm{EA}$, ou seja, procuramos descrever o tipo de abordagem das questões ambientais feita pelos professores de Química, bem como os aspectos que, além do conhecimento químico, são enfatizados quando essa abordagem extrapola os tópicos de conteúdos que os professores afirmaram possibilitar o tratamento dessa temática.

\section{EA convencional, conservadora ou conservacionista}

Alguns dos professores entrevistados revelaram-nos fatores de seu entendimento e, também, de sua prática em relação à EA, a qual se caracteriza como uma EA convencional, conservadora ou conservacionista. Esses fatores estão relacionados a pensamentos e atitudes que evidenciam a concepção de EA que o professor possui, conforme mostram os relatos apresentados abaixo:

“[...] en falo também de cada um fazer a sua parte, então é na sala... Inclusive, agora eu comecei a fazer atividades em rascunho pros meus alunos. Algumas escolas ficaram observando... "O que tem do outro lado, professora?", "Do outro lado é um rascunho", e eu comecei a fazer isso este ano pra justamente preservar [...]". (P01, dez anos de experiência no ensino de Química)

"O ser bumano é o grande agente destruidor do ecossistema, e isso acaba interferindo na sua vida diária, como o excesso de poluição, o aquecimento global... as intempéries... inclusive, catástrofes naturais...". (P02, 16 anos de experiência no ensino de Química)

"Acho que comportamento, explicar que o quanto você acha que se eu economizar na minha água que eu escovo dente não vai faz̧er diferença, mas começa a mostrar esse volume num dia, numa semana, num ano, se cada pessoa tentasse economizar...”. (P04, dois anos de experiência no ensino de Química) 
Esses fragmentos nos revelam alguns dos princípios da EA Convencional, sobretudo os trechos que relacionam as "pequenas atitudes" que cada um pode tomar, "cada um fazendo a sua parte", e ainda o excerto: "nós que somos os culpados". Tais fragmentos são integrantes de um discurso que culpa a humanidade por todos os problemas pelos quais estamos passando, porém ninguém direciona a questão para o contexto referente ao desenvolvimento de nossa sociedade e à consequente exploração dos recursos naturais. Ninguém aponta o sistema econômico vigente nem mesmo destaca a atividade das indústrias nesse histórico de degradação e exploração. Esses trechos são facilmente comparados a algumas das características da EA dita Convencional. De acordo com Loureiro (2004, p. 80), esta se caracteriza como uma

Educação como ato comportamental pouco articulado à ação coletiva e à problematização e transformação da realidade de vida, despolitizando a práxis educativa. Como conseqüência, parte-se da crença ingênua e idealista de que as mudanças das condições objetivas se dão pelo desdobramento das mudanças individuais, faltando complexidade no entendimento das relações constituintes do ser.

Todos os discursos que preconizam a EA como conjunto de atitudes e ações corretas, porém individualizadas, na esperança de que a sua soma resulte em soluções globais, caracterizam prontamente esse tipo de EA, pois não levam em conta as demais relações existentes. Outra característica importante é a responsabilidade da humanidade quanto à causa dos problemas ambientais, como salienta Loureiro (2004, p. 80):

[...] O Homo sapiens fica reduzido a um organismo biológico, associal e a-histórico. O resultado prático é a responsabilização pela degradação posta em um ser humano genérico, idealizado, fora da história, descontextualizado socialmente. Por exemplo, isso fica evidente quando ouvimos os recorrentes discursos de que a humanidade é responsável pela degradação planetária, sem que se situem os grupos sociais, o modo como estamos organizados e produzimos, numa fala que, pela ausência de concretude, fica sem efeito prático na mudança das relações sociais que o atual modo de ser da natureza.

Somente P11, em seu depoimento, apresentou-nos alguns fatores que corroboram uma EA Crítica, Transformadora e Emancipatória. Em vários pontos da entrevista, o professor aponta as atividades agrícolas e industriais como grandes causadoras de problemas ambientais e ainda critica o trabalho de "formiguinhas" que é amplamente incentivado.

"[...] Mas é a indústria e a agricultura que têm que mudar, não é nós (risos), os habitantes em comum aí. Não é o uso doméstico que vai causar esse maior dano. [...] Novamente a questão do início, né, os agentes envolvidos aí, e aípensando em emissões atmosféricas, quem mais provoca essas de novo é a tal da agricultura e a tal da indústria, e ai não é um indivíduo comum que vai... Tem campanha agora 
Leite, R. F.; Rodrigues, M. A.

pra pintar telhado todo de branco, carro vai ser tudo branco... e as indústrias vão poder continuar emitindo a mesma quantidade de efluentes e tudo mais e a gente preocupado em fazer aquele trabalho de formiguinha? Não que não seja legal, é legal isso, mas desde que isso aí entre lá pra dentro da indústria". (P11, seis anos de experiência no ensino de Química)

A principal crítica que P11 faz ao longo de seu depoimento é muito semelhante a um dos fundamentos da EA Emancipatória: trata-se da crítica aos reducionismos, por meio dos quais uma EA Convencional aborda, por exemplo, apenas os efeitos dos impactos ambientais, sem se deter nas causas desses impactos (LIMA, 2004). Assim, concordando com a crítica, evidenciamos o dizer de Loureiro (2004, p. 73) sobre a falta de dialética entre economia, política e ética:

[...] podemos nos educar para novos modos de consumo, mas isto tem que se ligar a um novo modo de produção e, no capitalismo, tais atividades adquiririam uma escala mundial impossível de ser alterada totalmente senão em termos globais. É preciso ter claro que a atuação educativa específica ocorre no conjunto das relações em que esta se insere, pela qual se define, é condicionada e/ou visa alterar, necessitando estar combinada com outros locais, agentes, saberes e poderes.

\section{Objetivos da abordagem de questões ambientais}

Alguns dos professores entrevistados utilizam o tema meio ambiente como forma de tornar o ensino de Química mais atraente. O professor deseja que o aluno perceba uma aplicabilidade dos conceitos que estão sendo trabalhados na disciplina, que os "visualize", que se sinta motivado a estudar mais, que goste de Química. Enfim, as prioridades do professor estão relacionadas unicamente aos conceitos químicos, e o tema meio ambiente é considerado um recurso para ensinar Química, como se verifica nos relatos a seguir:

"[o objetivo é] que o aluno consiga relacionar o conceito cientifico que você tá passando, que ele consiga aplicar, consiga visualizar. Então não adianta você passar um exemplo técnico, um exemplo de laboratório, que ele não tem conbecimento, que ele não tem vivência, ele não consegue relacionar". (P04, dois anos de experiência no ensino de Química)

"Conseguir enxergar uma aplicaşão da química... Ajudar aos alunos a entenderem mais o conteúdo, tratando de um tema mais visivel, mais palpável, para ensinar. Então é mais ilustrativo. [...]". (P05, dois anos e meio de experiência no ensino de Química)

"Eu procuro pra eles terem uma visão melhor da química, né, pra eles gostarem da quimica [...] Que ela não é uma matéria invisivel (risos), que ela tá ao nosso redor, a gente usa, a gente respira, né. Que ela não é nada abstrata porque nós 
Educação Ambiental: reflexões sobre a prática ...

somos química, né. Então não tem nada de abstrato. [...]". (P10, seis anos de experiência no ensino de Química)

Nos relatos acima, pode-se perceber uma intenção de contextualizar o conhecimento veiculado, buscando atenuar a distância entre o que é ensinado na escola e o que o aluno vivencia e conhece. Quando o professor fala em um tema mais "visível" ou "palpável", ele se refere a algo que esteja próximo do aluno e que pertença ao seu cotidiano, mesmo afirmando que o referido tema seja apenas ilustrativo.

Porém, considerando os estudos de Vaitsman e Vaitsman (2006), que apontam a contextualização como contribuição para a minimização da dicotomia teoria-prática - como forma de evitar que os alunos apliquem os conhecimentos adquiridos em sala de aula somente na resolução de exercícios, sem relacioná-los com o que ocorre no seu dia a dia -, podemos dizer que essa intenção é válida somente se houver mudança na metodologia de ensino. Apenas indicar onde é possível "encontrar" o conhecimento químico em nada contribui para o ensino dos conceitos químicos e nem mesmo atribui a devida importância às questões ambientais. Para os mesmos autores, a discussão de situações de impactos ambientais, por exemplo, deve possibilitar a construção de conceitos significativos para a melhoria da qualidade de vida dos alunos, além de enfatizar a importância da Química nesses processos.

Nesse sentido, apenas ilustrar o conceito químico que está sendo ensinado ou utilizar os temas ambientais como instrumentos de motivação são atitudes que não caracterizam a EA nem enriquecem esse conceito.

\section{Experiências vivenciadas envolvendo a questão ambiental}

Questionamos os professores sobre algo que já tivessem feito e que estivesse relacionado à questão ambiental. Diante dessa questão, deparamo-nos, na maioria das respostas, com a prática da EA de maneira muito pontual, eventual até. A participação em projetos, feiras de ciências ou visitas foi o exemplo mais apontado pelos professores entrevistados, como mostram os relatos abaixo:

“[...] É, já faz uns três anos que na outra também a gente trabalhou a questão do lixo, mas era aquela coleta seletiva, e também vendia e trocava latinha, trocava 0 pet, a caixa de leite longa vida... toda a escola participava [...]". (P01, dez anos de experiência no ensino de Química)

'[...] E também trabalhei... com a EJA... não que seja especificamente, vamos dizer assim, o tema meio ambiente, mas en fiz. um projeto que era de metais pesados, que en cultivei alface. [...]. E aí eu peguei uma solução com chumbo... não lembro que metais eu peguei, mas eram metais pesados, enfim, pequei na universidade, ai fiz várias concentrações, e tudo em triplicata. [...] Dai eu consegui associar os metais pesados, baterias de celular, pilhas, baterias, tudo, descarte como tinha que ser, características, doenças...”. (P03, sete anos de experiência no ensino de Química) 
Leite, R. F.; Rodrigues, M. A.

"Química e meio ambiente? (Silêncio...) Não... Não me lembro de nada, não... Bom, que nós tivemos o ano passado até é: o projeto da técnica, era sobre os resíduos, do laboratório, né. Então, foi trabalhado o ano todo, com todas as turmas, né. Por exemplo, era sempre pedido pra, por exemplo, se eu tivesse lá água com açúcar, eles podiam jogar na pia, agora se fosse água com dicromato, ou água com qualquer outro produto, ai eles tinha que recolher num vidro. Ai a gente explicava o que ia ser feito: se ia destilar, evaporar, dava o destino". (P06, vinte anos de experiência no ensino de Química).

"Em meio ambiente. Eu tenho uma colega minha, que ela aprendeu fazer vaso, né, com caixa de leite longa vida, e dai eu ensinei meus alunos [...] tem alunos que eles começaram a fazer pra vender, e eu achei que sortiu bastante resultado. Assim foi. Envolven cinco aulas das minhas, que era na noite dela e minha, mas os alunos gostaram bastante, porque dai eles começaram a pensar que a partir dali, dava pra reciclar outras coisas, fazer outros objetos, e foi, en achei uma experiência muito legal. Essa parte de... foi colocado também que é... essa embalagem não pode ser jogada fora, quanto que ela estaria poluindo o meio ambiente, quanto tempo ia demorar pra se decompor, e ali ela é utilizada hoje, né, comentei assim, nas casas, né, como antitérmico...". (P10, seis anos de experiência no ensino de Química)

Com os relatos acima, é fácil perceber que os professores de Química abordam as questões ambientais em momentos especiais, com características particulares que demandam atividades diferenciadas, como é o caso das feiras de ciências, dos projetos e das oficinas.

Nos relatos de P03, quando cita o experimento da alface, e de P06, quando trata da substituição dos reagentes, encontramos exemplos de abordagem das questões ambientais durante as aulas, ao longo do desenvolvimento do conteúdo químico. A prática realizada e descrita pelo professor P03 é muito boa, uma vez que aborda uma questão ambiental grave e rica em conteúdo da Química. Já a prática de P06 caracteriza-se como algo pontual, pois se não houver uma discussão sobre o porquê da substituição dos reagentes, não se pode chamar essa atividade de EA. No entanto, considerando os princípios da Química Verde, essa já seria uma boa oportunidade para o professor estabelecer uma relação entre a Química e o meio ambiente, sem destacar a primeira como um mal para o segundo.

Atividades pontuais, como a realização de visitas e projetos sem continuidade, são características de uma EA acrítica que, sem a preocupação de transformar, destina-se, apenas, a um adestramento dos indivíduos, como diria Brügger (2004), já que não propicia oportunidades de reflexões que possam levar a uma mudança de pensamentos e ações, mas apenas conduz os estudantes à reprodução de habilidades técnicas. No entanto, as atividades descritas acima revelam que alguns professores possuem iniciativas para relacionar questões ambientais às aulas de Química. 
Educação Ambiental: reflexões sobre a prática ...

\section{EA permeando o desenvolvimento dos conceitos químicos}

Alguns professores afirmaram trabalhar os temas ambientais durante o desenvolvimento do conteúdo químico, fato que, ao primeiro olhar, pode significar uma EA constante. Porém, vemos que, quando o professor assume a postura de trabalhar o tema apenas quando o conteúdo permite, pode não haver qualquer outra preocupação a não ser a de exemplificar o conhecimento químico.

"(Silêncio...) Eu acho que assim... a gente fala da parte de... en fir discussões já
de... teve um acidente lá com um tipo de ácido: "o que vocês acham que deve é
feito?", "por que... vocês iam jogar água? Com o caminhão de bombeiro...", "ah...
não", "o que a gente pode jogar, então?", "ah, uma base", "que base?",
"como é que a gente vai conseguir uma base barata, rápida, em grande em quanti-
dade... pra isolar a área, pra não ter problema"? Então, assim, este tipo de discus-
são assim que eu trago".(P04, dois anos de experiência no ensino de Quí-
mica)

"Tá... Deixa eu lembrar... (Silêncio...) mais o trabalho com exemplos. Laboratório, as aulas práticas, mas são mais... tradicionais, não tem muita coisa a ver com o meio ambiente". (P05, dois anos e meio de experiência no ensino de Química)

"Na verdade, o que eu faço é... Procuro trabalhar dentro da aula, né [...] o que en tenho proposto pra este ano, e eu vou fazer com minhas turmas de quimica, e chama Visita Nada Ecológica. Então, foi uma aula que eu organižei e eu escolbi o titulo dessa forma, porque é uma visita ao tratamento de água, ao tratamento de lixo e ao tratamento de esgoto". (P07, 12 anos de experiência no ensino de Química)

Nos trechos transcritos, o que caracteriza a EA no decorrer do desenvolvimento do conteúdo químico são os exemplos apresentados e os exercícios discutidos com os alunos. Aqueles professores que associam as questões ambientais aos conteúdos químicos desenvolvidos em aula vão além daqueles que só conseguem trabalhar em momentos específicos, como as feiras de ciências ou projetos. Somente o entrevistado P07 afirmou trabalhar dessa forma, porém só mencionou algumas visitas que pretendia realizar com seus alunos. Há que se ressaltar que essa maneira de abordar as questões ambientais, ou seja, apenas quando o conteúdo permite e, ainda, apenas com exemplos do conceito a ser desenvolvido, pode não caracterizar a EA. Como foi dito pelos professores, pouca coisa além do conteúdo químico é trabalhada nesses exemplos. Sendo assim, novamente esbarramos em um ensino com características conteudistas e com uma EA Convencional, que apenas aponta as questões ambientais, mas não as desenvolve nem as problematiza (LIMA, 2004). 
Leite, R. F.; Rodrigues, M. A.

\section{Menção a aspectos sociais, políticos e/ou econômicos}

Alguns dos professores entrevistados colocam em evidência, além dos conceitos químicos, fatores sociais, políticos e/ou econômicos, quando estes se relacionam ao tema ambiente em suas aulas, como se pode perceber nos relatos abaixo:

"Eles começam a fazer perguntas também, eles visualizam assim do dia-a-dia e que buscam o conbecimento, entender aquela informação: "ah, por que que a sacola é biodegradável?". E ai você começa a explicar que tem uma velocidade de decomposição mais rápida e tal, e aí eles começam a perguntar por que não se utiliza muito mais, e aí você fala dos custos, que isso é muito mais caro: "ah, se você fosse comprar uma bolacha que o pacote fosse biodegradável e fosse três reais esse pacote... o que vocês iriam...". Ai, eles param e pensam: "ah, com certeza, o de um real". Ai, eles começam a pensar realmente [...]". (P04, dois anos de experiência no ensino de Química)

'[...] a gente comenta, né, quando a gente vai no mercado, porque é que hoje tem mercado que tá fornecendo sacolas de tecido, né, dai eu comento: "lembram que antigamente eles levavam a estopa de casa pra pegar o arroz, não tinha toda aquela parte de sacola, sacola". [...] Coloco um pouco de economia, um pouco de esgotamento [...]". (P10, seis anos de experiência no ensino de Química)

"Questão ética, política... E são os fatores que vão poder faz̧er a mudança. Só o conbecimento químico não adianta. [...]". (P11, seis anos de experiência no ensino de Química)

A utilização de temas sociais como o meio ambiente, relacionando-os aos aspectos políticos e econômicos, é uma característica do ensino para a formação do cidadão (SANTOS; SCHNETZLER, 2003). Mesmo sem assumir essa postura de mudança em relação ao ensino tradicional de Química, esses professores já demonstram certa tendência a abandonar o conteudismo, justificado por si mesmo, ao abordarem tais aspectos em suas aulas.

\section{Busca pela conscientização dos alunos, enfatizando uma mudança de comportamento}

A maioria dos professores entrevistados busca a conscientização dos alunos, no sentido de fazê-los refletir sobre a necessidade de haver uma mudança de comportamento.

"[...] Conscientização. É o que eu começo... Quando eu falo de lixo, eu já falei pra eles assim: "Quando você joga o teu lixo, fecha tua sacolinha de lixo ali, joga na lixeira, leva pro caminhão coletar, a grande maioria pensa: meu problema tá resolvido, e na verdade, tá começando uma etapa. Pra onde está indo esse lixo? será que realmente eu precisaria ter gerado toda aquela quantidade de lixo? [...] Então, conscientização". (P04, dois anos de experiência no ensino de Química) 
"Eu trabalho dentro da parte da ética, de consumo consciente [...] Então, por exemplo, é difícil... até pra mim... quando eu vou escolher um pacote de bolacha, eu escolho a que, além do pacotão, tá embalada em vários pacotinhos (risos). Porque eu acho mais prático. Mas eu tento entender e tento ensinar que esse é o errado, e não o certo, porque, ao invés de eu ter um pacotão de lixo, eu vou ter o pacotão e vários pacotinhos de lixo (risos)". (P07, 12 anos de experiência no ensino de Química)

"Bom, ai vem a postura, consciência. Eu nem chamo mais conscientização. Eu já usei muito essa palavra, agora eu chamo mudança de hábito. Pra mim, é mudança de hábito. Não tem que conscientizar. Vamos pegar só um tema bem fácil: o que ele faz. com o lixo em casa, o tempo que ele demora pra tomar banho...". (P09, trinta anos de experiência no ensino de Química)

Esse tipo de preocupação dos professores reflete a maneira pela qual o tema meio ambiente foi incorporado à educação formal. Segundo Leff (2005, p. 243), essa incorporação se limitou a internalizar valores de conservação da natureza, destacando-se apenas os problemas mais visíveis, como a contaminação dos recursos e o manejo do lixo, por exemplo; assim, a assimilação do tema reduziu-se à incorporação de uma "consciência ecológica". No nosso entendimento, não há como conscientizar o outro; o que podemos é fornecer condições que poderão suscitar mudanças de atitude, ou seja, criar situações que possibilitem, aos alunos, espaço para a reflexão e ação. Com esse processo, os alunos poderão se sentir propensos a realizarem mudanças, devido à própria consciência. Dessa forma, concordamos com Sato (2001), quando a autora ressalta que ninguém conscientiza ninguém; não há como dar consciência a alguém, pois cada grupo social vivencia e constrói sua representação e, consequentemente, seus valores. Assim, este conscientizar que os professores mencionam não pode ser entendido como a simples adoção acrítica de um discurso.

\section{Tópicos de conteúdos}

No decorrer de cada entrevista, os professores citaram vários conteúdos da disciplina de Química que permitem uma abordagem das questões ambientais, conforme indicam as falas apresentadas abaixo:

"[...] Foi possivel trabalhar tabela periódica, propriedades dos elementos quimicos, características deles, ai todos os conceitos... [...] Ai, dei textos... exemplos lá do Césio 137. Então, assim, dava para trabalhar muita coisa, porque tinha muitos exemplos, muitas questões que... Meu Deus... era fantástico. Elementos radioativos... Tudo... Dava para trabalhar emissões de radiação alfa, beta e gama”. (P03, sete anos de experiência no ensino de Química)

"Ai (suspiro)... tem lá, primeiro ano, tabela periódica, por exemplo, origem dos elementos. Ai, tem que relacionar com o meio ambiente. Reações, funções inorgânicas, tem como relacionar com o meio ambiente. Segundo ano, equilíbrio químico, 
Leite, R. F.; Rodrigues, M. A.

cinética... No terceiro ano também, só tá um pouco mais limitado pelas funções orgânicas... Mas dá, sim". (P05, dois anos e meio de experiência no ensino de Química)

"[...] Que nem lá, tão vendo soluções e né "o que acontece quando você coloca um, por exemplo, um inseticida no solo, que vai acabar poluindo o solo, a água vai diluir, né, a chuva vai diluir, vai acabar na água, vai misturar...". Daí, pra trabalhar ali, sim, você diæ: "ah, vai alterar o $\mathrm{pH}$ da água" porque dai eles já viram". (P10, seis anos de experiência no ensino de Química)

'[...] E aí, tu pegar e ensinar pra eles, tu dá aula, de novo lá, a questão de chuva ácida, você pode tá trabalhando a questão de ácidos... Ai, tu tem os gases dissolvidos... Como é que tudo ocorre... Tu acaba ensinando pra eles o que são esses fenômenos, chuva ácida também é normal, toda chuva é ácida, mas em função do aumento da concentração de alguns dos gases, vai aumentar a acidez [...]." (P11, seis anos de experiência no ensino de Química)

Com os exemplos destacados, é possível perceber que é do conhecimento desses professores que se estabelece a relação entre os conceitos químicos e as questões ambientais. Consideramos que este seja um aspecto positivo no trabalho do professor, desde que ele saiba identificar os pontos nos quais é possível abordar o tema ambiental, como se almeja nesta pesquisa, e isso se caracteriza como uma vantagem para ele, ao elaborar suas aulas. Entretanto, salientamos que, mais importante do que visualizar os conceitos químicos possíveis de serem relacionados às questões ambientais, é saber escolher a metodologia adequada para trabalhar essas questões. Vaitsman e Vaitsman (2006) indicam a contextualização como a metodologia ideal para abordar as questões ambientais nas aulas de Química e apresentam uma série de atividades que possibilitam esse tipo de abordagem. Segundo os autores,

A metodologia sugerida para a contextualização do ensino de Química permite a construção de conceitos fundamentais através da leitura de textos sobre impactos ambientais regionais e globais os quais podem ser adaptados e ampliados pelo educador para outras situações que agridam o meio ambiente. (VAITSMAN; VAITSMAN, 2006, p. 15)

\section{Atitudes perante o meio ambiente}

Podemos perceber que alguns professores, ao comentarem sobre a importância do meio ambiente, ressaltam o fator destruição, apontando o homem como grande agente destruidor, na maioria dos casos. Além disso, os professores acreditam que podem dar consciência aos seus alunos apenas enfatizando os problemas do meio ambiente, ou as mudanças de postura que seriam necessárias, aspecto que, como já mencionamos, é difícil de acontecer de maneira tão simples. Novamente concordamos com Sato (2001), pois é necessário que o indivíduo vivencie ou reflita sobre determinadas questões para tomar consciência de suas responsabilidades. Além de objetivarem a conscientização dos alunos, tais professores buscam o 
Educação Ambiental: reflexões sobre a prática ...

estabelecimento de um entendimento do todo, ou seja, de uma visão global, e não pontual dos problemas.

“[...] Então eu gostaria que os alunos percebessem... é... começassem aqui a perceber... a destruição que nós estamos causando no planeta. Vamos divulgar pra mais pessoas dessa forma, trabalhando com os alunos a conscientização de um melhor aproveitamento dos recursos do planeta". (P02, 16 anos de experiência no ensino de Química)

"Olha, o que eu espero é poder conscientizar eles um pouquinho, né, da importância de tudo isso. [...]. No caso do lixo, eu sei que se eu separar o meu lixo, eu não vou fazer grande diferença nesse Brasil imenso, né, só que... eu vou estar ajudando; pelo menos, a minha consciência vai estar limpa, né?’. (P06, vinte anos de experiência no ensino de Química)

"Relacionar com o conteúdo teórico e despertar também pra eles aquela consciência de que nós podemos fazer alguma coisa, né, podemos contribuir com o meio ambiente". (P12, nove anos de experiência no ensino de Química)

Nas falas dos professores, identificamos suas preocupações com alguns dos problemas ambientais, que acabam por caracterizar uma "[...] tendência a querer atuar de uma forma determinada diante de um tipo de situação [...]” (TOMAZELLO; FERREIRA, 2001, p. 199). Porém, isso não significa que os professores possuam comportamentos e hábitos responsáveis em relação ao meio ambiente, ou mesmo à Educação Ambiental. Por comportamento, entende-se a ação concreta (TOMAZELLO; FERREIRA, 2001); entretanto, nas falas dos professores, não conseguimos observar nada de concreto, no que tange ao meio ambiente e à Educação Ambiental. O que se percebe são apontamentos que tendem a certa preocupação com o meio ambiente e à sua conservação. Tais aspectos identificam uma EA convencional (LOUREIRO; LIMA, 2004), conservadora (GUIMARÃES, 2004) ou conservacionista (BRÜGGER, 2004), baseada na conservação dos recursos e em pequenas atitudes individuais (LOUREIRO, 2004).

\section{Considerações finais}

Procuramos, neste trabalho, discutir algumas características da prática pedagógica do professor de Química do Ensino Médio, no que tange à relação entre conceitos químicos e meio ambiente. Para a consecução de tal objetivo, entrevistamos alguns professores, e foi analisando o conteúdo de seu discurso que pudemos assinalar alguns aspectos de seu trabalho.

No que diz respeito às questões ambientais abordadas em sala de aula, esta pesquisa revelou que, quando isso ocorre nas aulas de Química, as questões ambientais apresentam-se, na maioria dos casos, com a função de ilustrar o conteúdo químico, sem maiores discussões a respeito de sua amplitude social e política. A preocupação do professor sempre encerra uma postura conteudista e, até mesmo, tradicional de ensino de Química.

Pudemos identificar também que as concepções de Educação Ambiental desses professores se baseiam numa visão antropocêntrica e tradicional, tanto que suas falas apontam 
Leite, R. F.; Rodrigues, M. A.

alguns traços de uma EA convencional, conservadora e conservacionista, que pouco relaciona os vários fatores envolvidos na questão ambiental. Mesmo percebendo as possibilidades de relacionarem os conceitos químicos à questão ambiental, os professores só o fazem por meio de exemplificações, sem qualquer aprofundamento. Além disso, privilegiam aspectos nos quais as ações individuais e a responsabilização acrítica da humanidade fazem parte do discurso utilizado.

Dessa forma, pudemos identificar e caracterizar a prática pedagógica dos professores em relação à EA, descortinando o que pensam sobre a EA nas aulas de Química, ou seja, o que pensam sobre a relação entre a Química e o meio ambiente, entre a EA e o ensino de Química.

Ainda com relação à problemática ambiental, é importante destacar a ênfase que os professores deram à falta de formação ou a má-formação profissional nesse quesito. Assim, fica evidente que a prática pedagógica do professor é reflexo da formação inicial recebida. Portanto, faz-se necessário repensar a prática pedagógica dos professores e, também, os currículos dos cursos de licenciatura em Química, que ainda privilegiam a racionalidade técnica. Talvez a partir do momento em que os cursos de licenciatura em Química atribuírem a devida importância às questões ambientais ao longo das disciplinas, o professor formado tenha melhores condições de estabelecer as diversas relações entre o conhecimento químico e os aspectos social, político, econômico e ambiental.

\section{Referências}

BARDIN, L. Análise de conteúdo. São Paulo: Martins Fontes, 1977.

BRASIL. Lei n. 9.795, de 27 de abril de 1999. Dispõe sobre a educação ambiental, institui a Política Nacional de Educação Ambiental e dá outras providências. Diário Oficial [da]

República Federativa do Brasil, Brasília, 28 abr. 1999. Seção 1. Disponível em: <http:// www.dji.com.br/leis_ordinarias/1999-009795/1999-009795.htm>. Acesso em: 15 mar. 2009.

. Secretaria da Educação Fundamental. Parâmetros Curriculares Nacionais: temas transversais - meio ambiente/saúde. Brasilia: Secretaria de Educação Fundamental, MEC/SEF, 1997. v. 9

BRÜGGER, P. Educação ou adestramento ambiental. 3. ed. Chapecó: Argos, 2004.

CARVALHO, I. C. M. Educação ambiental crítica: nomes e endereçamentos da educação. In: LAYRARGUES, P. P. (Coord.). Identidades da educação ambiental brasileira. Brasília: Ministério do Meio Ambiente, Diretoria de Educação Ambiental, 2004. p. 13-24.

FLORIANI, D.; KNECHTEL, M. R. Educação ambiental: epistemologia e metodologias. Curitiba: Vicentina, 2003. 
Educação Ambiental: reflexões sobre a prática ...

GUIMARÃES, M. Educação ambiental crítica. In: LAYRARGUES, P. P. (Coord.).

Identidades da educação ambiental brasileira. Brasília: Ministério do Meio Ambiente, Diretoria de Educação Ambiental, 2004. p. 25-34.

LEFF, E. Saber ambiental: sustentabilidade, racionalidade, complexidade, poder. 4. ed. Petrópolis: Vozes, 2005.

LIMA, G. F. C. Educação, emancipação e sustentabilidade: em defesa de uma pedagogia libertadora para a educação ambiental. In: LAYRARGUES, P. P. (Coord.). Identidades da educação ambiental brasileira. Brasília: Ministério do Meio Ambiente, Diretoria de Educação Ambiental, 2004. p. 85-111.

LOUREIRO, C. F. B. Educação ambiental transformadora. In: LAYRARGUES, P. P. (Coord.). Identidades da educação ambiental brasileira. Brasília: Ministério do Meio Ambiente, Diretoria de Educação Ambiental, 2004. p. 65-84.

LÜDKE, M.; ANDRÉ, M. E. D. A. Pesquisa em educação: abordagens qualitativas. São Paulo: EPU, 1986

PENTEADO, H. D. Meio ambiente e formação de professores. 4. ed. São Paulo: Cortez, 2001.

SANTOS, W. L. P.; MORTIMER, E. F. Uma análise de pressupostos teóricos da abordagem C-T-S (Ciência - Tecnologia - Sociedade) no contexto da educação brasileira. Ensaio:

Pesquisa em Educação em Ciências, Belo Horizonte, v. 2, n. 2, p. 133-162, 2000.

.; SCHNETZLER, R. P. Educação em química: compromisso com a cidadania. 3. ed. Ijuí: Unijuí, 2003.

SATO, M. Debatendo os desafios da educação ambiental. In: CONGRESSO DE EDUCAÇÃO AMBIENTAL PRÓ MAR DE DENTRO, 1., 2001, Rio Grande. Anais... Rio Grande: Mestrado em Educação Ambiental, FURG \& Pró Mar de Dentro, 2001. p. R14-R35.

THOMPSON, P. A voz do passado: história oral. São Paulo: Paz e Terra, 2002.

TOMAZELLO, M. G. C.; FERREIRA, T. R. C. Educação ambiental: que critérios adotar para avaliar a adequação pedagógica de seus projetos? Ciência $\boldsymbol{\&}$ Educação, Bauru, v. 7, n. 2, p. 199-207, 2001.

VAITSMAN, E. P.; VAITSMAN, D. S. Química \& meio ambiente: ensino contextualizado. Rio de Janeiro: Interciência, 2006.

Artigo recebido em outubro de 2010 e aceito em fevereiro de 2011. 